\title{
Effects of feeding tuna oil on the lipid composition of pig spermatozoa and in vitro characteristics of semen
}

\author{
J. A. Rooke ${ }^{1}$, C-C. Shao ${ }^{2 *}$ and B. K. Speake ${ }^{3}$ \\ ${ }^{1}$ Animal Biology Division, SAC, Craibstone Estate, Aberdeen AB21 9YA, UK; ${ }^{2}$ Department \\ of Agriculture, University of Aberdeen, Aberdeen AB24 5UA, UK; and ${ }^{3}$ Department of \\ Biochemistry and Nutrition, SAC, Auchincruive, Ayr KA6 5HW, UK
}

The aim of the present study was to characterize the effects of feeding tuna oil on the lipid and fatty acid composition of boar spermatozoa and to relate changes in composition to boar semen characteristics. Ten boars were paired by age and allocated to one of two diets (five boars per diet). The diets, which were offered for 6 weeks, consisted of a basal diet that was either unsupplemented or supplemented with $30 \mathrm{~g}$ tuna oil $\mathrm{kg}^{-1}$ diet. Adding tuna oil to the diet increased the ether extract concentration of the diets fed from 65 to $92 \mathrm{~g} \mathrm{~kg}^{-1}$ dry matter and supplied $10.5 \mathrm{~g}$ long chain polyunsaturated $(\mathrm{n}-3)$ fatty acids per $\mathbf{1 0 0} \mathrm{g}$ total fatty acids. There were no changes in semen fatty acid composition after 3 weeks of feeding tuna oil. However, after 5 and 6 weeks, the proportions (g per $100 \mathrm{~g}$ total fatty acids) of 22:6(n-3) in sperm phospholipid fatty acids were increased from 34.5 to $42.9 \mathrm{~g}$ by feeding tuna oil and 22:5(n-6) decreased from 29.8 to $17.9 \mathrm{~g}$. No changes were observed in other sperm lipids or seminal plasma phospholipids as a result of the diets fed. Feeding tuna oil increased the proportion of spermatozoa with progressive motility and with a normal acrosome score and reduced the proportion of spermatozoa with abnormal morphologies.

\section{Introduction}

The phospholipids of mammalian spermatozoa have a characteristic fatty acid composition, the most distinctive feature of which is a very high proportion of long chain $\left(\mathrm{C}_{22}\right)$ highly polyunsaturated fatty acids. In most mammals, docosahexaenoic acid (22:6(n-3)) is the dominant polyunsaturated fatty acid although, in several species, docosapentaenoic acid (22:5(n-6)) is also a major component (Neill and Masters, 1972; Poulos and White, 1973; Poulos et al., 1973; Darin-Bennett et al., 1974; Jain and Anand, 1976; Salem et al., 1986; Lin et al., 1993; Kelso et al., 1997a). Pig spermatozoa share the above characteristics, although the reported proportions of polyunsaturated fatty acids in phospholipids and the relative amounts of the (n-6) and (n-3) fatty acids vary (Ahluwalia and Holman, 1969; Johnson et al., 1972; Evans and Setchell, 1979; Paulenz et al., 1995).

In human spermatozoa, 22:6(n-3) performs an essential function in promoting optimal fertility, since reductions in the amount of this fatty acid in sperm lipids have been correlated with reductions in sperm concentration and in spermatozoa with progressive motility and normal morphology (Nissen and Kreysel, 1983; Zalata et al., 1998; Conquer et al., 1999). During ageing of chickens (Kelso

*Present address: Chinese Culture University, Taipei City 111, Taiwan

Email: j.rooke@ab.sac.ac.uk et al., 1996, 1997b; Cerolini et al., 1997) and bulls (Kelso et al., 1997a), reductions in the output, quality and fertilizing ability of spermatozoa are associated with decreased proportions of $\mathrm{C}_{20-22}$ polyunsaturated fatty acids in sperm phospholipids.

Diets fed to pigs commonly contain large amounts of cereals, with most supplementary protein being added in the form of oilseed meals such as soya-bean and rapeseed. Thus, dietary fatty acids typically have a $(n-6):(n-3)$ ratio of greater than $6: 1$ and contain no long chain polyunsaturated (n-3) fatty acids. If 22:6(n-3) is essential for optimal fertility in pig spermatozoa, as it is in human spermatozoa (Nissen and Kreysel, 1983; Zalata et al., 1998; Conquer et al., 1999), then it is possible that pig diets provide a suboptimal supply of 22:6(n-3) for spermatogenesis. This suboptimal supply may arise either from a deficit of (n-3) fatty acids per se or a reduced synthesis of 22:6(n-3) from 18:3(n-3) owing to competition between (n-6) and (n-3) fatty acids for desaturase enzymes (Sprecher, 1989). Furthermore, when pregnant sows were offered diets containing either $18: 3(n-3)$ or 22:6(n-3), feeding 18:3(n-3) did not result in increases in 22:6(n-3) in sow adipose tissue or piglet tissues at birth, indicating a limited biosynthetic capacity of 22:6(n-3) to 18:3(n-3) (Rooke et al., 2000). To date, studies in which fish oil has been fed to boars (Paulenz et al., 1995, 1999) have not improved fertility, although these studies were carried out against a background of good fertility. The aim of the current study was to characterize the effects of feeding tuna oil on the lipid and fatty acid composition of boar spermatozoa and to 
relate changes in composition to boar semen characteristics using boars of different ages with potentially different sperm quality.

\section{Materials and Methods}

\section{Boars}

Between June and August 1997, initial samples of semen were obtained from 12 Large White boars (Sus scrofula), which were in use for the production of semen for commercial artificial insemination at A. Simmers Ltd, Mains of Cairnbrogie, Old Meldrum, Aberdeenshire. The boars were maintained in individual pens $(3.0 \mathrm{~m} \times 3.2 \mathrm{~m})$ in a ventilated building in which temperature was maintained below $25^{\circ} \mathrm{C}$. Of the 12 boars, ten were paired by age and one of each pair randomly assigned to one of two diets (see below). At the start of the experiment, the age of the boars ranged from 395 to 761 days.

\section{Diets}

The diets were formed from a basal diet consisting of $660 \mathrm{~g}$ barley, $243 \mathrm{~g}$ wheatfeed, $34 \mathrm{~g}$ extracted rapeseed meal, $38 \mathrm{~g}$ whole rapeseed and $25 \mathrm{~g}$ mineral-vitamin supplement per $\mathrm{kg}$ fresh mass, which the boars had been fed before the experiment. With the exception of additional $\alpha$ tocopherol acetate (as an antioxidant), the basal diet was fed alone as an unsupplemented control diet. The tuna oil (30 g $\mathrm{kg}^{-1}$, Tuna Orbital Oil, Scotia Pharmaceuticals Ltd, Carlisle) was added to the basal diet as a supplement. The diets were fed as follows. The unsupplemented boars were fed $2.5 \mathrm{~kg}$ daily, consisting of $2.0 \mathrm{~kg}$ basal diet and $500 \mathrm{~g}$ of a premix obtained by mixing basal diet with $1.5 \mathrm{~g} \alpha$-tocopherol acetate $\mathrm{kg}^{-1}$. Similarly, for the supplemented diet, boars were fed $2.575 \mathrm{~kg}$ daily, consisting of $2.0 \mathrm{~kg}$ basal diet and $575 \mathrm{~g}$ of a premix obtained by mixing basal diet with $150 \mathrm{~g}$ tuna oil and $1.5 \mathrm{~g} \alpha$-tocopherol acetate $\mathrm{kg}^{-1}$. Therefore, the final concentrations of added $\alpha$-tocopherol acetate were 300 and $291 \mathrm{mg} \alpha$-tocopherol acetate $\mathrm{kg}^{-1}$ for the unsupplemented and supplemented diets, respectively. The premixes were prepared at the start of the experiment and stored at $-20^{\circ} \mathrm{C}$ until required. The compositions of the diets as fed are given (Table 1) and they were fed to the boars for 6 weeks.

\section{Semen collection}

Semen was collected from all boars $(n=12)$ in duplicate at the start of the experiment and after 3, 5 and 6 weeks of feeding the experimental diets (single sample per week; $n=10)$. Semen was collected using the gloved hand technique (Hancock and Hovell, 1959); the boars were accustomed to the procedure, which was carried out once or twice per week by the same person. The total volume of the sperm-rich fraction was recorded and the sperm-rich fraction was filtered through gauze. The semen was maintained at $39^{\circ} \mathrm{C}$ until evaluation on the farm and during transport to the laboratory for centrifugation.

\section{Semen evaluation}

Raw semen density was estimated using a colorimeter and diluted for use with a commercial extender (Androhep, Minitub, Tiefenbach). The number of spermatozoa in diluted semen was determined in duplicate using a Makler counting chamber and phase-contrast microscopy. Sperm motility was also determined in duplicate using the Makler chamber: 100 spermatozoa were classified as having progressive motility, being motile but not progressive or being immotile.

\section{Morphological analysis}

Stained semen smears were prepared by mixing diluted semen with nigrosin-eosin stains to evaluate sperm

Table 1. Composition of diets fed to the boars

\begin{tabular}{lcr}
\hline & Unsupplemented & Tuna oil \\
\hline Dry matter $\left(\mathrm{g} \mathrm{kg}^{-1}\right)$ & 916 & 918 \\
Crude protein $\left(\mathrm{g} \mathrm{kg}^{-1}\right.$ dry matter) & 150 & 143 \\
Ether extract $\left(\mathrm{g} \mathrm{kg}^{-1}\right.$ dry matter) & 65 & 92 \\
Fatty acids (g per 100 g total fatty acids) & & \\
$16: 0$ & 15.8 & 16.2 \\
$16: 1(\mathrm{n}-7)$ & 2.9 & 3.6 \\
$18: 1(\mathrm{n}-9)$ & 33.9 & 28.8 \\
$18: 2(\mathrm{n}-6)$ & 36.0 & 26.5 \\
$18: 3(\mathrm{n}-3)$ & 7.9 & 6.3 \\
$20: 4(\mathrm{n}-6)$ & $\mathrm{ND}$ & 0.7 \\
$20: 5(\mathrm{n}-3)$ & $\mathrm{ND}$ & 2.0 \\
$22: 6(\mathrm{n}-3)$ & $\mathrm{ND}$ & 8.5 \\
Total $(\mathrm{n}-6)$ & 36.0 & 28.1 \\
Total $(\mathrm{n}-3)$ & 8.0 & 17.3 \\
Ratio $(\mathrm{n}-6):(\mathrm{n}-3)$ & 4.5 & 1.6 \\
\hline
\end{tabular}

ND: none detected. 
morphology and viability or with Giemsa stain to evaluate acrosome structures. The mixed semen and stain were incubated for $2-5 \mathrm{~min}$ at $37^{\circ} \mathrm{C}$ before preparing smears on microscope slides and then leaving them to dry. Stains were obtained from Sigma Chemical Co. (Poole). The nigrosin-eosin-stained slides were evaluated by examining 100 spermatozoa per slide in duplicate slides. Viable spermatozoa were defined as those that did not take up stain. Spermatozoa were examined for the following abnormal morphologies: detached head, abaxial head, malformed head, damage to acrosome cap, bent tail, coiled tail and presence of cytoplasmic droplets. Giemsa-stained slides were examined similarly to determine the occurrence of abnormal acrosome structures (Pursel et al., 1972).

\section{Feed analysis}

Dry matter was determined by drying at $80^{\circ} \mathrm{C}$ for $24 \mathrm{~h}$. Crude protein content was determined by the Kjeldahl method and ether extract according to the method of the Ministry of Agriculture, Fisheries and Food (1992).

\section{Lipid extraction and analysis}

Approximately $20 \mathrm{ml}$ of the sperm-rich fraction of the ejaculate was transported to the laboratory at $39^{\circ} \mathrm{C}$. The spermatozoa were separated from the seminal plasma by centrifugation at $700 \mathrm{~g}$ for $20 \mathrm{~min}$ at $4^{\circ} \mathrm{C}$. The spermatozoa were re-suspended in the same volume of $9 \mathrm{~g} \mathrm{NaCl} \mathrm{I}^{-1}$ and re-centrifuged. This process was repeated twice. The washed spermatozoa and the seminal plasma were stored at $-20^{\circ} \mathrm{C}$ to await analysis.

Total lipid was extracted from the spermatozoa after homogenization in a suitable excess of chloroform-methanol $(2: 1, v / v)$ (Christie, 1982). The lipids were fractionated into their major classes (phospholipid, free cholesterol, triacylglycerol, free fatty acids and cholesterol ester) by thin layer chromatography on silica gel G using a solvent system of hexane:diethyl ether:formic acid (80:20:1, v/v). After visualization under UV light after spraying with $0.1 \%(\mathrm{w} / \mathrm{v})$ 2,7-dichlorfluorescein in methanol, the separated bands were scraped from the plates. Phospholipid was eluted from the plates by washing three times with $2 \mathrm{ml}$ methanol, and the other lipid classes were eluted with diethyl ether. The esterified lipid fractions were subjected to transmethylation by refluxing with methanol:toluene:sulphuric acid (20:10:1, v/v) in the presence of a pentadecaenoic acid standard (Christie et al., 1970). The resultant fatty acid methyl esters were analysed by a $1 \mu$ injection via a CP9010 autosampler (Chrompack, London) onto a $30 \mathrm{~m} \times 0.25 \mathrm{~mm}$ diameter, $0.25 \mu \mathrm{m}$ film thickness Carbowax capillary column (Econo-Cap, Alltech UK Ltd, Carnforth). The following temperature program was used to separate the fatty acids: $185^{\circ} \mathrm{C}$ for $2 \mathrm{~min}$; increase to $230^{\circ} \mathrm{C}$ at $5^{\circ} \mathrm{C} \mathrm{min}^{-1}$ and $24 \mathrm{~min}$ at $230^{\circ} \mathrm{C}$. Peak values were detected by flame ionization. Integration of the peaks using an EZ-Chrom Data Handling System (Speck Analytical, Alloa) enabled the determination of the fatty acid composition (percentage $\mathrm{w} / \mathrm{w}$ of total fatty acids). The amount of each lipid class was calculated by comparison of the total fatty acid peak areas with that of the pentadecaenoic fatty acid internal standard (Christie et al., 1970). Free cholesterol was determined by a colorimetric assay (Boehringer, Lewes).

\section{Statistical analysis}

Data for each individual abnormal morphology were summed to give a single value for cells with abnormal morphology in an ejaculate. The effects of feeding tuna oil were measured by a repeated measures ANOVA using Genstat (Lawes Agricultural Trust, 1987); sperm composition and characteristics at week 0 were used as covariates, and linear and quadratic orthogonal polynomials were used to assess the effects of time of feeding and of time $\times$ diet interactions. One boar was removed from the experiment for reasons unconnected with the diets fed and, therefore, data for 3, 5 and 6 weeks of feeding for the tuna oil supplemented group include an estimated missing value.

\section{Results}

Sperm characteristics in vitro are given (Table 2). Semen volume increased from week 3 to week 6 of the experiment (linear effect, $P<0.05$ ), whereas the proportion of spermatozoa with abnormal morphology decreased (linear effect, $P<0.01)$. Feeding tuna oil significantly increased sperm viability $(P<0.05)$ and the proportion of spermatozoa with progressive motility $(P<0.01)$ and with a normal acrosome score $(P<0.001)$. For sperm viability and spermatozoa with a normal acrosome score, these changes became more marked as the experiment progressed (linear diet $\times$ time interaction; $P<0.05$ for normal acrosome score).

The lipid and phospholipid fatty acid compositions of seminal plasma and spermatozoa at the start of the experiment are given (Table 3). The fatty acid compositions of cholesterol esters and triglycerides of spermatozoa are not shown. The fatty acid composition of cholesterol esters from spermatozoa were not influenced by the diets fed, and saturated (16:0 and 18:0,54\%) and monounsaturated $(18: 1,38 \%)$ acids were quantitatively the most important fatty acids. Seminal plasma lipids and lipid fatty acid composition were more variable than those of spermatozoa (Table 3) and were not influenced by feeding tuna oil (data not shown). The predominant lipids in seminal plasma were phospholipids and free cholesterol. Phospholipid fatty acids of seminal plasma contained smaller amounts of long chain polyunsaturated fatty acids than did spermatozoa phospholipids.

As the experiment progressed (Table 4), the amounts of cholesterol ester (quadratic effect, $P<0.01$ ) and free cholesterol (quadratic effect, $P<0.05$ ) in the spermatozoa increased and the amounts of phospholipid decreased 


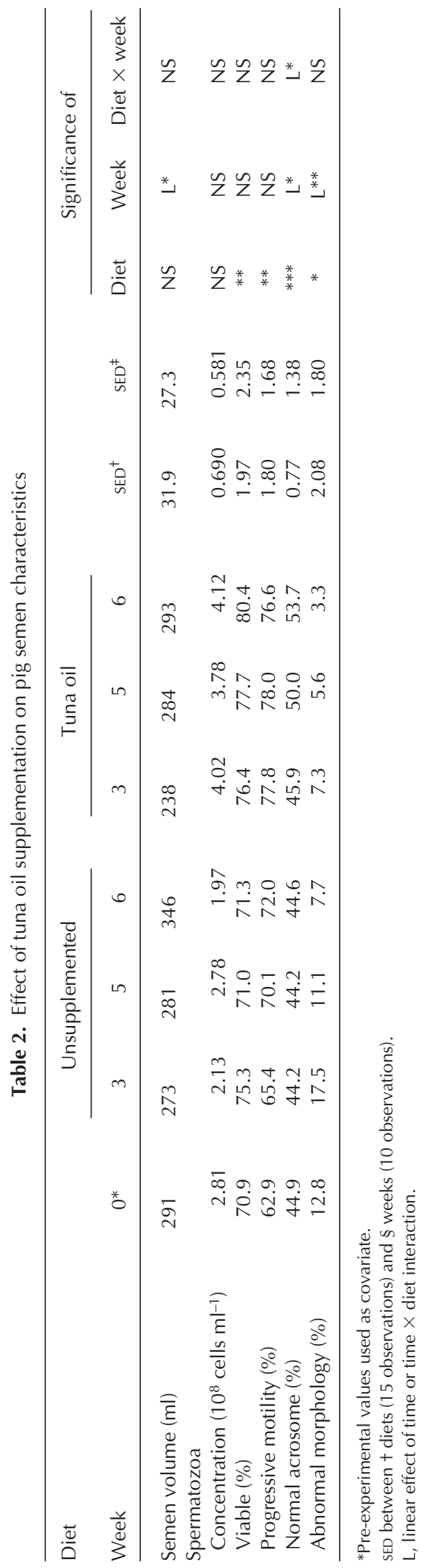


Table 3. Lipid composition of spermatozoa and seminal plasma from pig semen at beginning of experiment

\begin{tabular}{|c|c|c|c|c|}
\hline & \multicolumn{2}{|c|}{ Spermatozoa } & \multicolumn{2}{|c|}{ Seminal plasma } \\
\hline & Mean & Standard deviation & Mean & Standard deviation \\
\hline Total lipid* & 149 & 42.7 & 16 & 2.9 \\
\hline \multicolumn{5}{|c|}{ Lipids (g per 100 g total lipid) } \\
\hline Cholesterol & 32.8 & 5.91 & 45.7 & 9.18 \\
\hline Cholesterol ester & 1.2 & 0.61 & 9.4 & 5.86 \\
\hline Phospholipids & 61.9 & 5.10 & 37.6 & 8.75 \\
\hline \multicolumn{5}{|c|}{ Phospholipid fatty acids } \\
\hline Saturated & 28.1 & 13.32 & 28.5 & 1.51 \\
\hline Monounsaturated & 11.7 & 2.46 & 2.9 & 0.40 \\
\hline $18: 2(n-6)$ & 9.5 & 3.36 & 2.1 & 0.21 \\
\hline $20: 4(n-6)$ & 7.6 & 2.74 & 2.8 & 0.24 \\
\hline $22: 4(n-6)$ & 6.2 & 2.13 & 1.9 & 0.12 \\
\hline $22: 5(n-6)$ & 13.1 & 5.59 & 24.8 & 5.92 \\
\hline $22: 6(n-3)$ & 13.9 & 9.95 & 32.9 & 4.80 \\
\hline Total (n-6) & 40.7 & 9.38 & 33.5 & 4.89 \\
\hline Total (n-3) & 18.0 & 11.35 & 33.6 & 5.19 \\
\hline
\end{tabular}

Values are means for ten boars.

* $\mu$ g per $10^{8}$ spermatozoa; $\mu$ g per $\mathrm{ml}$ of seminal plasma. (linear effect, $P<0.01)$. When tuna oil was added to the diet, changes in fatty acid composition occurred only in phospholipid fatty acids. It should be noted that the method used to transmethylate phospholipid fatty acids measured only ester-linked fatty acids and not ether-linked fatty acids as occur in plasmalogens. Changes in phospholipid ester-linked fatty acids were noted after weeks 5 and 6 of the experiment and not after week 3 . Therefore, there were marked diet $\times$ time interactions. Feeding tuna oil decreased the (n-6) fatty acid proportions, principally of 22:4(n-6) and 22:5(n-6), in total phospholipid fatty acids and increased the 22:6(n-3) proportions. Therefore, the ratio of total (n-6) to (n-3) fatty acids and of $22: 5(n-6)$ to 22:6(n-3) significantly decreased after 5 weeks of feeding tuna oil.

\section{Discussion}

The objective of the present study was to evaluate whether feeding tuna oil changes sperm lipid composition and sperm characteristics in vitro.

The present evaluation of the composition of spermatozoa lipids and their fatty acids agreed broadly with previous studies on boar spermatozoa, with phospholipids being the most abundant lipid class (Komarek et al., 1965; Johnson et al., 1972). Phospholipids were also the dominant lipid in seminal plasma (Komarek et al., 1965; Johnson et al., 1969; Evans and Setchell, 1979). The most abundant fatty acids in sperm phospholipids were the long chain polyunsaturated fatty acids 22:5(n-6) and 22:6(n-3).
There is some variance among studies in the amounts of 22:5(n-6) and 22:6(n-3) reported in sperm phospholipids. For example, Johnson et al. (1972) reported 34\% 22:5(n-6) and 23\% 22:6(n-3); Evans and Setchell (1979) reported 24\% 22:5(n-6) and 43\% 22:6(n-3); and Paulenz et al. (1995) reported 11\% 22:5(n-6) and 29\% 22:6(n-3) (none of these studies reported either the age or diet of the boars from which semen was obtained; both of these may be important factors influencing phospholipid fatty acid composition). The analysis at the start of the present study produced values of $25 \% 22: 5(n-6)$ and $33 \% 22: 6(n-3)$.

Another factor that might explain differences in sperm fatty acid composition among studies is the presence of ether-linked fatty acids in pig spermatozoa (Evans et al., 1980; Brouwers et al., 1998). In the present study, etherlinked fatty acids were not quantified by the derivitization procedure used. Brouwers et al. (1998) quantified the different molecular species of phosphatidyl choline from pig spermatozoa and found that approximately $60 \%$ of the phosphatidyl choline contained ether-linked fatty acids at the $s n-1$ position. However, the ether-linked fatty acids were saturated and predominantly 16:0, and the long chain polyunsaturated fatty acids were confined to the $s n-2$ position of the glycerol moiety. Therefore, changes in phospholipid fatty acid composition in response to feeding tuna oil, which primarily involved the replacement of $22: 5(n-6)$ with 22:6(n-3), probably involved changes in the fatty acid esterified at the $s n-2$ position of both ether- and ester-linked fatty acids. The close relationship between $22: 5(n-6)$ and $22: 6(n-3)$ is confirmed by the highly signifi- 


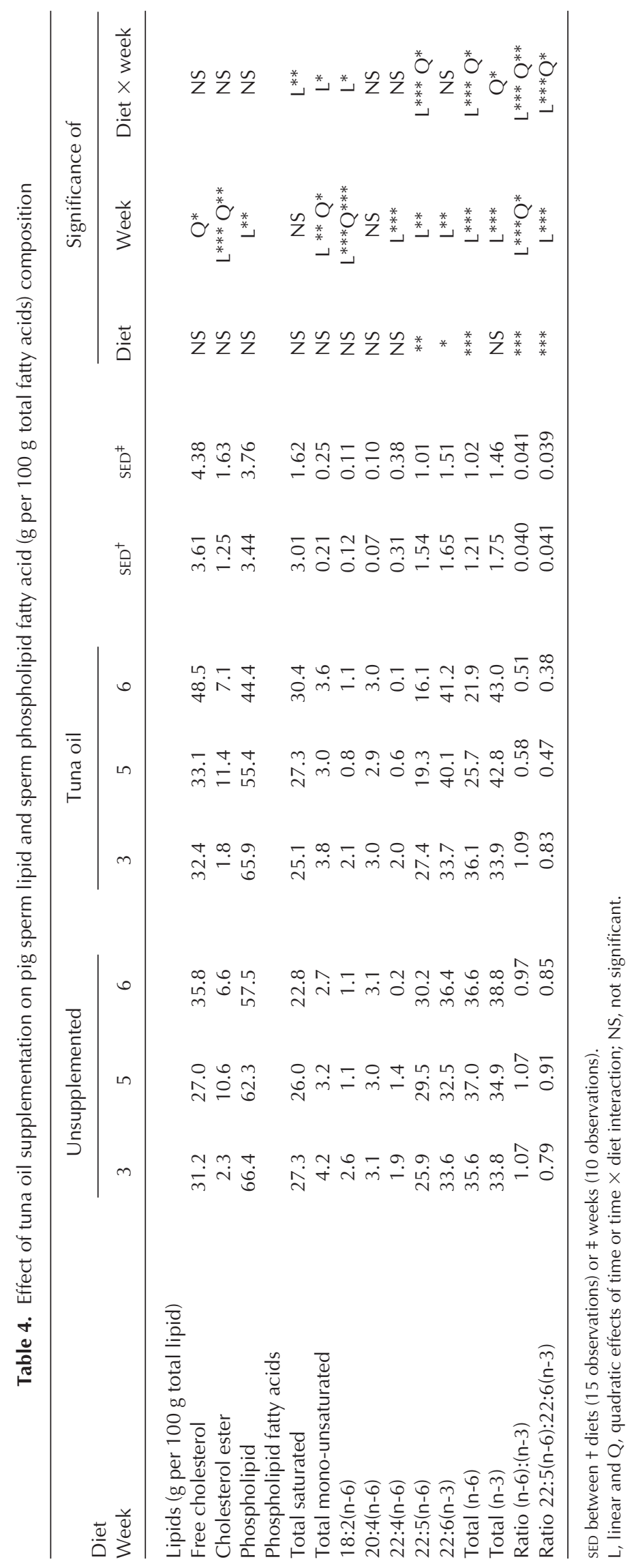


cant inverse relationship between the proportions of these two fatty acids $(r=-0.98 ; n=12 ; P<0.001)$ in sperm phospholipids in duplicate samples obtained from the boars before the start of the experiment.

Age-related changes in sperm lipid composition and sperm quality have been noted in cockerels (Kelso et al., 1997b) and bulls (Kelso et al., 1997a). In cockerels, the amounts of phosphatidyl ethanolamine and the dominant phospholipid fatty acid, 22:4(n-6) decreased with age, as did the fertility of the spermatozoa. In bulls, sperm concentration and motility decreased with age and there were associated changes in lipid composition. Total sperm phospholipids and phosphatidyl ethanolamine and the proportion of 22:6(n-3) in phosphatidyl ethanolamine and phosphatidyl choline all decreased with age. Kelso et al. (1997a) suggested that changes in the activities of desaturase enzymes required for the synthesis of the long chain polyunsaturated fatty acids may be responsible for the decline in 22:6(n-3) concentrations. Indeed Brenner (1989) has observed that, in rat testicles, $\Delta 6$-desaturase activity, the rate-limiting step in polyunsaturated fatty acid synthesis, decreased with age. Therefore, it appears that sperm lipid composition changes with age, with undesirable consequences for sperm quality. In the present study, the inverse relationship between 22:5(n-6) and 22:6(n-3) proportions in sperm phospholipids at the start of the experiment was related to the age of the boar, and the ratio of 22:5(n-6) to 22:6(n-3) was demonstrated to be correlated positively with the age of the boar $(r=0.82 ; n=12$; $P<0.001)$. Although the effects of age per se or long-term exposure to an inadequate diet could not be separated in the present study, these data imply a relationship between sperm phospholipid fatty acid composition and age in boars, as in other species (Kelso et al., 1997a,b), which may have functional consequences.

After 5 weeks of feeding tuna oil, there were changes in sperm phospholipid fatty acid proportions that were not apparent after 3 weeks feeding. Paulenz et al. (1995, 1999) have also fed fish oil (cod liver oil) to boars and reported changes similar to those observed in the present study in total sperm lipid fatty acids, that is, increases in 22:6(n-3) and decreases in 22:5(n-6) proportions in total sperm fatty acids. As in the present study, these changes became apparent only after 5 weeks of feeding the marine oil (Paulenz et al., 1995). Spermatogenesis and epididymal transport are reported to take 34 and 10 days, respectively, in boars (Swierstra, 1968). Therefore, it seems that there is a point during spermatogenesis after which exogenous 22:6(n-3) cannot be incorporated into sperm phospholipids. The present study (between days 11 and 23) and that of Paulenz et al. (1995; between days 15 and 21) both indicate that a similar stage of spermatogenesis is important.

Changes in semen characteristics were observed both in relation to the diets fed and to the duration of the experiment. The increase in progressive sperm motility and the decrease in the proportion of spermatozoa with abnormal morphology occurred in both control and tuna-oil- containing diets and, thus, may be related either to seasonal effects or to the inclusion of $300 \mathrm{mg} \alpha$-tocopherol $\mathrm{kg}^{-1}$ as an antioxidant in both the control and tuna oilcontaining diets. The $\alpha$-tocopherol was added to the diets to prevent oxidation of polyunsaturated fatty acids before feeding and represented the only change made to the diet the boars had been maintained on before the experiment. Marin-Guzman et al. (1997) have also found that inclusion of $220 \mathrm{mg} \mathrm{kg}^{-1} \alpha$-tocopherol in the diet of boars improved sperm morphology but differences were not apparent until 8 weeks after feeding commenced. Therefore, it is difficult to establish reasons for the time-related improvements in sperm quality.

Supplementing the diet of the boars with tuna oil changed sperm characteristics in the present study favourably, increasing viability, and the proportions of spermatozoa with progressive motility and normal morphology. This finding is in contrast to that of Paulenz et al. (1999) who found no improvements in sperm motility or acrosome integrity after fish oil supplementation. However, initial values for motility and acrosome integrity were markedly higher in the study of Paulenz et al. (1999) than they were in the current experiment (motility: 78 versus $71 \%$; acrosome integrity: 98 versus $45 \%$ ), indicating that responses to the inclusion of fish oil in the diet may depend on initial sperm quality.

In conclusion, feeding tuna oil to working boars specifically changed sperm phospholipid fatty acid proportions and improved sperm quality in vitro. Since, in humans, Zalata et al. (1998) have reported significant positive correlations between phospholipid 22:6(n-3) status and the concentrations of motile spermatozoa and spermatozoa with normal morphology, nutritional supplements of fish oil may also improve the quality of human spermatozoa.

SAC receives financial support from the Scottish Executive Rural Affairs Department. The authors wish to thank A. Burslem and the staff of A. Simmers Ltd, Mains of Cairnbrogie, Old Meldrum, Aberdeenshire for their assistance and use of facilities. The technical expertise of Ruth McCartney and Kenneth Maclsaac with regard to lipid analysis is also gratefully acknowledged.

\section{References}

Ahluwalia B and Holman RT (1969) Fatty acid composition of lipids of bull, boar, rabbit and human semen Journal of Reproduction and Fertility 18 431-437

Brenner RR (1989) Factors affecting chain elongation and desaturation. In The Role of Fats in Human Nutrition pp 45-80 Eds AJ Vergroesen and MA Crawford. Academic Press, San Diego

Brouwers JFHM, Gadella BM, van Golde LMG and Tielens AGM (1998) Quantitative analysis of phosphatidylcholine molecular species using HPLC and light scattering detection Journal of Lipid Research 39 344-353

Cerolini S, Kelso KA, Noble RC, Speake BK, Pizzi F and Cavalchini LG (1997) Relationship between spermatozoa lipid composition and fertility during ageing in the chicken Biology of Reproduction 57 976-980

Christie WW (1982) Isolation of lipids from tissues. In Lipid Analysis: Isolation, Separation, Identification and Structural Analysis of Lipids 2nd Edn pp 17-25 Pergamon Press, Oxford 
Christie WW, Noble RC and Moore JH (1970) Determination of lipid classes by gas chromatographic procedure Analyst 95 940-944

Conquer JA, Martin JB, Tummon I, Watson L and Tekpetey F (1999) Fatty acid analysis of blood serum, seminal plasma, and spermatozoa of normozoospermic versus asthenozoospermic males Lipids 34 793-799

Darin-Bennett A, Poulos A and White IG (1974) The phospholipids and phospholipid-bound fatty acids of dog and fowl spermatozoa Journal of Reproduction and Fertility 41 471-474

Evans RW and Setchell BP (1979) Lipid changes in boar spermatozoa during epididymal maturation with some observations on the flow and composition of boar rete testis fluid Journal of Reproduction and Fertility 57 189-196

Evans RW, Weaver DF and Clegg ED (1980) Diacyl, alkenyl, and alkyl ether phospholipids in ejaculated, in utero-, and in vitro-incubated porcine spermatozoa Journal of Lipid Research 21 223-228

Hancock JL and Hovell GJR (1959) The collection of boar semen Veterinary Record 71 664-665

Jain YC and Anand SR (1976) Fatty acids and fatty aldehydes of buffalo seminal plasma and sperm lipid Journal of Reproduction and Fertility 47 261-267

Johnson LA, Gerrits RJ and Young EP (1969) Quantitative analysis of porcine spermatozoa and seminal plasma phospholipids as affected by frequency of ejaculation Journal of Reproduction and Fertility 19 95-102

Johnson LA, Pursel VG and Gerrits RJ (1972) Total phospholipid and phospholipid fatty acids of ejaculated and epididymal semen and seminal vesicle fluids of boars Journal of Animal Science 35 398-403

Kelso KA, Cerolini S, Noble RC, Sparks NHA and Speake BK (1996) Lipid and antioxidant changes in semen of broiler fowl from 25 to 60 weeks of age Journal of Reproduction and Fertility 106 201-206

Kelso KA, Redpath A, Noble RC and Speake BK (1997a) Lipid and antioxidant changes in spermatozoa and seminal plasma throughout the reproductive period of bulls Journal of Reproduction and Fertility 109 1-6

Kelso KA, Cerolini S, Speake BK, Cavalchini LG and Noble RC (1997b) Effects of dietary supplementation with $\alpha$-linolenic acid on the phospholipid fatty acid composition and quality of spermatozoa in cockerel from 24 to 72 weeks of age Journal of Reproduction and Fertility 110 53-59

Komarek RJ, Pickett BW, Gibson EW and Jensen RG (1965) Lipids of porcine spermatozoa, seminal plasma and gel Journal of Reproduction and Fertility 9 131-136

Lawes Agricultural Trust (1987). Genstat 5 Reference Manual Clarendon Press, Oxford

Lin DS, Connor WE, Wolf DP, Neuringer M and Spector A (1993) Unique lipids of primate spermatozoa: desmosterol and DHA Journal of Lipid Research 34 491-499
Marin-Guzman J, Mahan DC, Chung YK, Pate JL and Pope WF (1997) Effects of dietary selenium and vitamin $\mathrm{E}$ on boar performance and tissue responses, semen quality, and subsequent fertilization rates in mature gilts Journal of Animal Science 75 2994-3003

Ministry of Agriculture, Fisheries and Food (1992) Analysis of Agricultural Materials 2nd Edn. HMSO, London

Neill AR and Masters CJ (1972) Metabolism of fatty acids by bovine spermatozoa Biochemical Journal 127 375-385

Nissen HP and Kreysel HW (1983) Polyunsaturated fatty acids in relation to sperm motility Andrologia 15 264-269

Paulenz H, Taugbøl O, Hofmo PO and Saarem K (1995) A preliminary study on the effect of dietary supplementation with cod liver oil on the polyunsaturated fatty acid composition of boar semen Veterinary Research Communications 19 273-284

Paulenz H, Taugbøl O, Kommisrud E and Grevle IS (1999) Effect of dietary supplementation with cod liver oil on cold shock and freezability of boar semen Reproduction in Domestic Animals 34 431-435

Poulos A and White IG (1973) The phospholipid composition of human spermatozoa and seminal plasma Journal of Reproduction and Fertility 35 265-272

Poulos A, Darin-Bennett A and White JG (1973) The phospholipid-bound fatty acids and aldehydes of mammalian spermatozoa Comparative Biochemistry and Physiology 46B 541-549

Pursel VG, Johnson LA and Rampacek GB (1972) Acrosome morphology of boar spermatozoa incubated before cold shock Journal of Animal Science 34 278-283

Rooke JA, Shanks M and Edwards SA (2000) Effect of offering maize, linseed or tuna oils throughout pregnancy and lactation on sow and piglet tissue composition and piglet performance Animal Science 71 289-299

Salem N, Kim HY and Yergey JA (1986) Docosahexaneoic acid: membrane function and metabolism. In Health Effects of Polyunsaturated Fatty Acids in Seafoods pp 263-321 Eds AP Simoupolos, RR Kifer and RE Martin. Academic Press, New York

Sprecher H (1989) Interactions between metabolism of n-6 and n-3 fatty acids Journal of Internal Medicine 225 5-11

Swierstra EE (1968) Cytology and duration cycle of the seminiferous epithelium of the boar: duration and spermatozoan transit through the epididymis Anatomical Record 161 171-186

Zalata AA, Christophe AB, Depuydt CE, Schoonjans F and Comhaire FH (1998) The fatty acid composition of phospholipids of spermatozoa from infertile patients Molecular Human Reproduction 4 111-118

Revised manuscript received 31 May 2000.

Accepted 23 August 2000. 